\section{COPPER MIRRORS.}

$M$ ETALLIC mirrors have been known from very early Iimes, and references to them are scattered through ancient literature. They were frequently elaborately decorated, and many of them possess the greatest interest as objects of art. Looking-glasses coated with an amalgam of quicksilver and tin came into use about the middle of the fifteenth century, but it is not known by whom they were originally invented. The details of their manufacture were, for long, carefully guarded as trade secrets, and were not made public until about a hundred years later. The process then described is in all essentials that still employed, wherever it has not been abandoned on account of the danger to workers from mercurial poisoning. Tin amalgam mirrors were most extensively used during the latter half of last century, but at the present time in England and Germany they are no longer made, as mirrors obtained by the actual deposition of metallic silver upon glass have displaced them.

This gradual but complete transformation of an important industry had its origin in an observation made by Liebig when investigating the properties of aldehyde, which he had recently discovered. He found that if a solution of silver nitrate to which some drops of ammonia had been added was warmed with the new compound, the silver oxide was immediately reduced, and that the reduction was accompanied by a peculiar phenomenon, the metal attaching itself to the glass in the form of a thin reflecting layer.

Liebig apparently did not at the time realise the importance of his discovery in relation to mirror making. This was first done by Thomas Drayton, of Brighton, who eight vears later, in 1843 , patented a process for manufacturing looking-glasses by a similar reduction of a silver solution by oil of cloves. His process did not prove a commercial success, and was soon abandoned in favour of one worked out by Liebig, in which milk-sugar was used as the reducing agent, and by various modifications of which all mirrors are now made.

Drayton's method at the time, however, excited widespread interest, and Faraday lectured upon it at the Royal Institution, silvering a number of large glass vessels during the lecture, to the great delight of his audience.

Faraday about this time made the interesting observation that a mirror-like deposit of copper upon glass could be obtained by heating plates of glass in a liquid made by dissolving a little oxide of copper in olive oil. Copper mirrors obtained thus are generally lacking in brilliancy, and if of any size are liable to be stained and discoloured in patches by decomposition products of the oil. Further, as the deposition of the metal only takes place at a tempcrature above that at which the oil decomposes, the process is excessively disagreeable to carry out, and as the oil is spoiled it is somewhat costly.

The writer has recently discovered ${ }^{2}$ that copper can be deposited upon glass from aqueous solution in. a film as brilliant as a similarly deposited silver one if a suitable reducing agent be employed. Such a reducing agent is found in phenyl hydrazine, which has the power of readily abstracting oxygen from copper oxide, leaving the copper in the metallic state, and being itself oxidised to benzene, nitrogen, and water.

To obtain a copper mirror by this process it is best to heat a mixture of one part of freshly distilled phenyl hydrazine and two parts of water until a clear solution is obtained, and to add about half its bulk of a warm saturated solution of cupric hydroxide in strong ammonia. Nitrogen is freely cvolved during the addition, and the cupric is reduced to cuprous hydroxide, which remains dissolved in the ammoniacal liquid, and does not undergo any appreciable further reduction until heated. A hot ro per cent. aqueous solution of potassium hydroxide is next to be added until a slight permanent precipitate of cuprous hydroxide is produced. If the colourless or pale yellow liquid thus made be cautiously heated in contact with a perfectly clean glass surface, metallic copper is devosited upon it in the form of a thin, coherent, perfectly reflecting lamina.

1 ":A Method of Debositing Copper upon Glass from Aquenus Solutions ir a Thin Brilliantly Refecting Film, and thus producing a Copper Mirror." Read before the Royal Society, November 2r, r9o7
As nitrogen is evolved during the reduction, and as tarry bye-products are formed in small quantity and float with the benzene produced to the surface of the liquid, if flasks or tube are to be coppered, devices must be adopted to keep the inner surfaces completely covered by the liquid from which the metal is being deposited, whilst allowing the gas to escape.

To obtain a film of sufficient thickness to be permanent, it is best to allow it to remain for an hour or so in contact with the warm reducing fluid, and not to pour off the latter until it has cooled to the temperature of the air. The surface of the deposited copper should then be well washed, first with water and afterwards with alcohol and ether, and finally should be protected from the slow oxidising action of the air by one or two coats of some quick-drying varnish.

The mirrors thus formed are very beautiful, for they show the splendid red colour of copper, and are more perfect in reflecting surface than the most highly polished metal. They are, moreover, if properly protected from the air, absolutely permanent. It is interesting to note that the copper is in the monovalent or cuprous state in which it is analogous to silver when it shows a similar capability of being deposited upon glass.

The surface on which the metal is deposited undoubtedly plays an important part in the process, since both silver and copper are deposited much more easily upon surfaces which have not been exposed for any length of time to the action of air or of water, and upon blown than upon polished glass.

It seems probable that the glass surface itself acts as a catalyser, and locally accelerates the reducing action.

\section{F. D. Chattaway.}

\section{GEOLOGICAI, SURVEY OF CANADA.}

SEVEN reports just received from the Geological Survey of Canada afford evidence of the valuable work that is being done in investigating the mineral resources of the Dominion. In Report No. $949 \mathrm{Mr}$. D. B. Dowling describes the Cascade coal basin, Alberta. He gives an outline of the geology and topography of the coalfield, and a detailed account of the character of the coal, thickness of seams, and extent of the measures. The report is accompanied by eight folding maps. The area illustrated on the map sheets lies within and to the east of the summit of the Rocky Mountains, the formations exposed giving a continuous section from the highest remaining beds of the Cretaceous down to the bottom of the Carboniferous. The coal is of Cretaceous age. In the hills. south of the Bow River ten or eleven seams, more than 4 feet. thick, have been found, while north of Bankhead, on the slope of Cascade Mountain, fourteen possibly workable seams occur. At the Bankhead colliery the coal is an anthracite, admirably suited for domestic purposes. A screening plant handling rooo tons a day has been crected. In Report No. $953 \mathrm{Mr}$. H. S. Poole describes the barytes deposits of Lake Ainslie and North Cheticamp, Nova Scotia and gives notes on the production, manufacture, and uses of barytes in Canada. Report No. 958 is devoted to Dr. G. C. Hoffmann's review of the work done in the laboratory of the survey during the year. It covers seventy-one pages, and contains a large amount of material of chemical and mineralogical interest. In Report No. $968 \mathrm{Mr}$. D. D. Cairnes gives an account of the geology of the Moose Mountain area of the disturbed belt of southern Alberta. Coal has been found in several places within this district, and natural gas has been found to the north, south, and east of this area in the same formations as those within it. In Report No. $977 \mathrm{Mr}$ R. W. Ells gives an account of the geology and natural resources of the area included in N.W. Quartersheet No. 122 of the Ontario and Quebec series, comprising portions of the counties of Pontiac, Carleton, and Renfrew. A lengthy list of fossils from the Chazy, Black River, Trenton, and Pleistocene formations comprised within the area, compiled by Dr. H. M. Ami, is appended. The minerals of economic value met with include iron ore, of which there is a workable deposit at Bristol mines, galena and zinc blende, mica, asbestos, 
gold, building stone, molybdenite, brick clays, ochre, and shell-marl. Report No. $97 \mathrm{x}$ is devoted to Mr. E. D. Ingalls's statistical review of the mineral industries of Canada for 1905. Although, unfortunately, somewhat bolated, this report, which covers $\mathrm{I} 74$ pages, gives complete and revised information for the year 1905 , advance provisional minerai statsstics of which were issued on March 2, 19006.

The grand total of the mineral production of Canada is valued at $13,905,034$. The most valuable mineral product is coal, which accounts for 25.2 per cent. of the whole. Metallic minerals contributed together 54 per cent., structural materials 14 per cent., and other nonmetallic minerals 5 per cent. Comparcd with the previous year, substantial increases are shown by all the leading industries, except in the case of gold, due to the continuous decrease of the Yukon placers. An interesting fcature is the remarkable increase in the output of cobalt. The large supply of this metal rendered available as a result of the discoveries at Cobalt, Ontario, had, however, a depressing effect on the market, and caused a very marked decrease in price. Lastly, Report No. IoI7 is devoted to a summary of the work done by the department of mines, Geological Survey, during the year 1907. It covers 132 pages, and its prompt publication deserves special commendation. There were in the field twenty parties, and the summary reports indicate that a large amount of valuable work was carried out, one of the chief results being the determination of enormous quantities of available bituminous coal in the Yukon region.

\section{UNITERSITY AND EDUCATIONAL INTELLIGENCE.}

ST. ANDrEws.-After a delay of more than a quarter of a century, at last, by the munificence of Mrs. Bell Pettigrew, the widow of the late professor of medicine and anatomy, a sum of $6000 l$. has been generously offered for the new museum of natural history of the Unjversity in which her husband labourcd so long. The present museum was erected by the Government in 1846 , and whilst its exterior is in keeping with the other substantial buildings in the quadrangle, its mode of lighting and its cases arc far behind date. Moreover, its crowded shelves not only render proper exhibition of the specimens impossible, but interfere with classification. In all probability a new lecture-room, a practical class-room, and rooms for curator and workers will be attached to the museum.

Canbridge.--The essays for which the Smith's prizes are adjudged are as follows (the names arc arranged in alphabetical order):- "Problems in the Wave-motion of Viscous Liquids," W. J. Harrison, Clare College; "On the Asymptotic Behaviour of Integral Functions of Zero Order, and Allied Problems," J. E. Littlewood, Trinity College; "On the Solution of Ordinary Linear Differential Equations having Doubly Periodic Coefficients," J. Mercer, Trinity College. The adjudicators are of opinion that the following essays are deserving of honourable mention, viz. :- "On Energy Accelerations and Partition of Energy," C. W. Follett, Trinity Hall; "On some Problems in the Theory of Metallic Reflection," H. R. Hassé, St. John's College; "The Geometry of Apolar Triads," W. P. Milne, Clare College ; "Perpetuant Syzygies of the $n$th Kind," H. T. H. Piaggio, St. John's College; "The Reflection of Plane Waves of Lisht at the Surface of a Medium of Spccial Periodic Character,' C. J. T. Sewell, Trinity College.

J. B. Hubrecht, Christ's College, has been elected to the Isaac Newton studentship, tenable from April 15, 1908 , to April 15, rori. The student will carry on a course of research in solar physics.

H. H. Arnold-Bemrose, Clare College; W. F. Sheppard, Trinity College; J. R. Sutton, Sidncy Sussex College; and A. Young, Clare College, have been approved by the seneral board of studies for the degree of Doctor in Science.

The Vice-Chancellor has announced to the Senate that donations of roool. each, in memory of the late $\mathrm{Mr}$. Walter K. Foster, have been promised towards the building fund of the new museum of archæology and of ethnology by
Mrs. Walter K. Foster, Mr. E. Bird Foster, Mr. C. F. Foster, and Mrs. E. Rawlings. Mr. Foster, in whose memory this munificent gift has been made, bequeathed to the University in $189 \mathrm{I}$ an extensive collection of prehistoric and Anglo-Saxon antiquities.

London.-Dr. H. T. Bovey, F.R.S., has been appointed Rector of the Imperial College of Science and Technology at South Kensington. Dr. Bovey was educated at Cambridge. He was twelfth wrangler in 1873 , and was elected a fellow of Queen's College. Before going to Canada in 1887 as professor of civil engineering and applied mechanics in McGill University, Montreal, he practised as a civil engineer, being engaged on important works on the Mersey. Under Dr. Bovey's direction the civil engineering department at McGill University acquired a considerable reputation both for undergraduate and research work. Recently a course of study in transportation was added to the seven other engineering courses. The work in this subject is liberally supported by the great Canadian railway companies. In 1888 Dr. Bovey was appointed dean of applied science in McGill University. It is well known that McGill University is excellently equipped both for engineering and applied science. In the chemistry department, for example, there are special laboratories for organic chemistry, physical chemistry, electrolytic analysis, iron and steel analysis, fire assaying, water analysis, determinative mineralogy, petrography, and photography. Dr. Bovey's experience both in engineering and science is therefore exceptionally wide. His literary output includes works on applied mechanics, theory of structures and strength of materials, and hydraulics, in addition to a number of scientific papers. He was elected a Fellow of the Roval Society in 1902 .

The London County Council proposes to make a grant of 5oool. for the current year to the Imperial College, without, however, pledging itself to contribute $20,000 l$. a year' in the future, as was intended if the original scheme for the college, by which it was proposed to establish a well-equipped institution for higher work in applied science and technology, independent of other institutions at South Kensington, had been carried out.

By the will of the late Mrs. Rylands, the Victoria University, Manchester, will receive the sum of $50,000 l$. Owens College, Manchester, 25,00ol.; and Mansfield College, Oxford, ro, oool.

THE British Medical Journal announces that Prof. Wilhelm Erb has given the University of Heidelberg a donation of $5000 l$., one half to be applied for the benefit of students and assistants and their maintenance in hospital when required, the other towards the promotion of scientific rescarch by students.

We have received from Messrs. Swan Sonnenschein and Co., Ltd., copies of the 1908 issues of "The Public Schools Year-book and Preparatory Schools Year-book" (price 3s. 6d. net), and "The Schoolmasters Year-book and Directory" (price $7 s$. 6d. net). Both books have become well known to educational workers as useful volumes of reference. The annual dealing specifically with the public schools, those, that is, which are connected with the Headmasters' Conference, provides details concerning the public schools which a parent seeking a school for his boy wishes to know. But the book contains much other useful information about preparatory schools, scholarships available, and the public examinations which qualify for entrance into the professions. There is, in addition, a section dealing with the various professions themselves which should prove invaluable to fathers whose sons have completed their school careers. The second volume appeals more directly to schoolmasters and others concerned in the administration of education. The extensive organisations throughout the country for the administration of secondary education are summarised; there is a chronicle of educational events during 1907; and particulars are given about educational societies and publications, examinations and inspecting bodies, and miscellaneous matters. More than half the volume is devoted to a verv complete directory providing detailed information concerning the qualifications and experience of masters teaching in secondary schools. 